\title{
Safety of Longer Size Stent in Treating De-Novo Long Coronary Lesion: Outcome at 1.5 Years Follow-Up, A Single Center Experiences
}

\author{
AHM Waliul Islam¹, Shams Munwar², Azfar H. Bhuiyan³, AQM Reza², Sahabuddin Talukder², Tamzeed Ahmed², \\ Nighat Islam ${ }^{4}$, Atique bin Siddique ${ }^{4}$, Intekhab Yousuf ${ }^{5}$, Zia Ur Rahman ${ }^{5}$, M S Alam $^{3}$
}

\begin{abstract}
:
Background: Percutaneous coronary intervention (PCI) of long lesions by long single stent or overlapping multiple stent might have higher incidences of ISR due to increased metal burden as well as coronary intervention increase cost of hospital stay. Therefore, our primary aim of our study was to evaluate the longterm safety of treating long lesion by a single longer size stent and its follow-up by coronary angiogram and or clinical evaluation at our OPD.

Methods: patient who had gone through $\mathrm{PCl}$ from the year 2014 to mid Oct 2017 at our center, had longer lesion and were treated by more than $38 \mathrm{mmstent}$ were selected and analyzed. Total 255(Male 213: Female 42) patients were enrolled in this study, underwent elective $\mathrm{PCl}$ and follow up CAG at on average 1.5 yrs. Total 267 stents were deployed in 255 patients, in some of the patient had double vessel disease to treat. Mean age for both male: female was(55:56) yrs. Associated Coronary artery disease (CAD) risk factors were Dyslipidemia, Hypertension, Diabetes Mellitus, Positive FH for CAD and Smoking (all male), CKD, Hypothyroidism.
\end{abstract}

Results: Among the study group; 192 (75.3\%) were hypertensive; $189(74.1 \%)$ were Dyslipidemic, $126(49.4 \%)$ patients were Diabetic, positive FH 74(29.4\%), CKD 8 (3.1\%), Hypothyroidism $2(0.8 \%)$ and $104(40.8 \%)$ were all male smoker. Common stented territory was, LAD $126(49.4 \%)$, RCA $115(45.1 \%)$, and LCX 24(9.4\%).Among the total patient population, Single vessel stented were $236(92.5 \%)$ and DVD $19(7.5 \%)$. Total 267 stents were deployed, among them $48 \mathrm{~mm}$ were in total $159(59.6 \%)$; among $40 \mathrm{~mm}$ were stented in $61(22.8 \%)$ and $38 \mathrm{~mm}$ in $47(17.6 \%)$ vessels. At an average follow-up period of 1.5 years, all stented territory remain patent without any residual stenosis.

Conclusion: We conclude that treating de-novo coronary long lesion by a single longer size stent is safe without any residual stenosis at an average followup period of 1.5 yrs. Thus, to reduce chances of recurrent ISR, hospital re-admission and reduce hospital cost as well.

Key Wards: CAG, PTCA, PCI, DES, Long lesion, Stents

(Bangladesh Heart Journal 2018; 33(2): 106-111)

Introduction:

Treating long segment coronary lesion is always a challenge for interventionist to deal with. Percutaneous Coronary Intervention ( $\mathrm{PCl}$ ) by implanting a stent inside a coronary artery, has been shown to decrease the morbidity of acute closure of the vessel. ${ }^{1}$ Clinical and angiographic restenosis rates in selected lesions are reduced with coronary stenting as

1. Associate Consultant, Dept. of Invasive and Interventional Cardiology, Apollo Hospitals Dhaka.

2. Senior Consultant, Dept. of Invasive and Interventional Cardiology, Apollo Hospitals Dhaka.

3. Specialist, Dept. of Invasive and Interventional Cardiology, Apollo Hospitals Dhaka.

4. Senior Registrar, Dept. of Invasive and Interventional Cardiology, Apollo Hospitals Dhaka.

5. Registrar, Dept. of Invasive and Interventional Cardiology, Apollo Hospitals Dhaka.

Dept. of Invasive and Interventional Cardiology, Apollo Hospitals Dhaka

Address of Correspondence: Prof. Dr. AHM Waliul Islam, Interventional Cardiologist at Apollo Hospitals Dhaka. Cell: +8801713228884 , E-mail: drwali62@hotmail.com

DOI: http://dx.doi.org/10.3329/bhj.v33i2.39306

Copyright ( $\odot 2017$ Bangladesh Cardiac Society. Published by Bangladesh Cardiac Society. This is an Open Access articles published under the Creative Commons Attribution-NonCommercial 4.0 International License (CC BY-NC). This license permits use, distribution and reproduction in any medium, provided the original work is properly cited and is not used for commercial purposes. 
compared with angioplasty. ${ }^{2-3}$ Multiple or long coronary stents are now being implanted in long lesion or in tandem lesions.

Longer lesion usually need a longer segment to be covered by stents, and thus may require more than one stent. Both greater stented length and higher number of stents may exacerbate the risk of restenosis and mask direct relation lesion length and lumen narrowing after coronary stenting 4-5Previously, treating long lesion by multiple overlapping stents has shown significant stent restenosis ${ }^{6-8}$

Treatment of long and diffuse coronary lesion have been associated with increased risk of restenosis after PCl. A higher angiographic restenosis of $58 \%$ reported after plain balloon angioplasty. ${ }^{9}$ Although, the advent of bare metal stents was a breakthrough, was not successful in treating long coronary lesion. Implantation of multiple stents in treating long lesion resulted in diffuse in-stent restenosis. ${ }^{10}$ With the advent of drug eluting stents in treating long segment coronary lesion, there has been dramatic reduction of ISR and repeat revascularization as compared to BMS. ${ }^{11-12}$

With the advent of modality of treating coronary stents of different DES, treating of a single long de-novo coronary lesion by using a single stent in our Bangladeshi patient population yet to known clearly. Therefore, we have carried out this non randomized prospective cohort of patient who had $\mathrm{PCl}$ with a stent $>38 \mathrm{~mm}$ in length. Our primary aim of the study was to evaluate the long-term safety of treating long lesion by a single longer size stent and its follow-up by coronary angiogram and or clinical evaluation at our OPD.

\section{Methods:}

Patients who underwent PCI from the year 2014 to May 2018 at our center, had longer lesion and treated by a long stent of more than $38 \mathrm{mmstent}$ were selected and analyzed. Patient had baseline pre- $\mathrm{PCl}$ coronary angiogram either at our center or elsewhere. Based on QCA images and stented segment, lesions were divided into three group according to the length of the stented segment: Stented segment length $38 \mathrm{~mm}$, stented segment length $40 \mathrm{~mm}$ and stented segment length 48mm. Total 255(Male 213: Female 42) patients were enrolled in this study, underwent elective $\mathrm{PCl}$ and follow up CAG at on average 1.5 years. Total 267 stents were deployed in 255 patients, in some of the patient had double vessel disease to treat. Lesions prepared by a low profile balloon, followed by stenting of the lesion. Further, post-dilatation was done by $3.0-3.5 \mathrm{~mm}$ non-compliant balloon with 16 20ATM for better optimization of stent. Mean age for both male: female was (55:56) yrs. Associated CAD risk factors were Dyslipidemia, High Blood pressure, Diabetes Mellitus, Positive FH for CAD and Smoking (all male), CKD, Hypothyroidism.

Long lesion: In the present study patient who were treated with stent from $38 \mathrm{~mm}$ onward were defined as long lesion. The procedure was considered successful with residual stenosis of $<25 \%$ was left after stent placement. Death of any cause, myocardial infarction and Target lesion revascularization either by repeat percutaneous coronary intervention $(\mathrm{PCl})$ or Coronary Artery Bypass Grafting (CABG) were considered as major adverse cardiac events. The diagnosis of MI was established in presence of chest pain, ECG changes of $Q$ in 1 or more leads with raised CKMB or Trop I. The follow-up protocol included phone contact or medical visit at the OPD or coronary angiogram. All patients were given informed consent for intervention and control CAG.

\section{Drug Therapy}

All the patients received Aspirin $300 \mathrm{mg}$ and Clopidegrol as a loading dose $300 \mathrm{mg}$ prior to $\mathrm{CAG}$ and $\mathrm{PCI}$ with or without Ticarel or Prasureland continued for 9-12 months and received atorvastatin along with standard medical management for CAD. During the procedure, an intravenous heparin bolus $(100 \mathrm{IU} / \mathrm{Kg}$ ) and GP IIb/IIla receptor blocker Integrillin were administered as required. The use of GP Ilb/ IIla Receptor blocker was recommended as per protocol.

\section{Stents:}

Among the stent used; Sirolimus Eluting stent (Biotronik), Everolimus Eluting stent (Boston Scientific and Abbott vascular) and Taxus (Boston Scientific), Resolute Integrity (Medtronic)

Data: Data were presented as mean \pm SD with percentage.

\section{Results:}

Table 1. shows demographic profile of Studied population. Female were older than male (Male 55: Female 56) yrs. Male are having more cardiovascular risk factors than female, as smokers were all male (Male 2.8: Female 2.5). Female were more obese than male(BMI male 26: Female 28). Table 2. Shows the contrast used and serum creatinine level in studied patient before and after the procedure. Average contrast uses in both sexes are $75 \mathrm{ml}$ and $\mathrm{s}$. creatinine level were remaining almost identical in both pre and post procedure. Female has poorly controlled diabetes (Male vs Female:8.9 vs $10.7 \mathrm{mmol} / \mathrm{L})$. Table.3. Shows the territory wise the different size stent used in both male and female. Interestingly, it has been shown that in both sexes average vessel diameter in all three territories was less than $3 \mathrm{~mm}$ in diameter. Figure 1. Shows the percentage distribution of coronary stents according to territory. Figure 2. shows the stented territory, LAD 46\%, RCA 45\%, LCX 9\%. Figure 3. Shows the distribution stents according its length in $\mathrm{mm}$. Figure 4. Shows the of CAD risk factors. 189(74.1\%) were Dyslipidemia, 192 (75.3\%) were hypertensive; 126 (49.4\%) patients were Diabetic, positive FH 74 (29.4\%), CKD 8 (3.1\%), Hypothyroidism 2 (0.8\%) and 104 (40.8\%) were all male smoker.Figure 5 . shows the stenting of LAD with along $2.75 \times 48 \mathrm{~mm}$ stent. Figure 6 . Shows the stent patency after $1.5 \mathrm{yrs}$. 
Table-I

Profile of patient

\begin{tabular}{lcc}
\hline & Male & Female \\
\hline Number & 39 & 9 \\
Age $(\mathrm{yrs})$ & $55.2 \pm 10.0$ & $56.4 \pm 9.4$ \\
$\mathrm{BMI}\left(\mathrm{kg} / \mathrm{m}^{2}\right)$ & $25.9 \pm 2.3$ & $27.9 \pm 3.5$ \\
$\mathrm{SBP}(\mathrm{mmHg})$ & $131 \pm 18$ & $133 \pm 18$ \\
$\mathrm{DBP}(\mathrm{mmHg})$ & $79.0 \pm 9.1$ & $79 \pm 12$ \\
No Risk Factor & $2.8 \pm 1.0$ & $2.5 \pm 0.8$ \\
\hline
\end{tabular}

Data were presented as Mean \pm SD
Table-II

Contrast used and S. Creatinine level

\begin{tabular}{lcc}
\hline & Male & Female \\
\hline Contrast in ml & $76.1 \pm 12.4$ & $75.8 \pm 10.7$ \\
S.Creatinine(pre) & $1.25 \pm 0.4$ & $1.18 \pm 0.34$ \\
S. Creatinine (post) & $1.24 \pm 0.3$ & $1.1 \pm 0.21$ \\
RBS(mmol/L) & $8.9 \pm 4.1$ & $10.7 \pm 2.8$ \\
HbA1C & $6.95 \pm 4.1$ & $7.4 \pm 6.6$ \\
\hline
\end{tabular}

Data were presented as Mean \pm SD

Table-III

Average size of Stent used with inflation pressure

\begin{tabular}{|c|c|c|c|c|c|c|c|c|c|c|}
\hline \multirow[b]{2}{*}{ LAD } & \multirow[b]{2}{*}{ M } & \multicolumn{3}{|c|}{ Length (mm) } & \multicolumn{3}{|c|}{ Diameter(mm) } & \multicolumn{3}{|c|}{ Inflation Pressure (ATM) } \\
\hline & & 43.5 & \pm & 0.3 & 2.8 & \pm & 0.3 & 16.0 & \pm & 1.9 \\
\hline & $\mathrm{F}$ & $44 . .0$ & & 4.9 & 2.7 & & 0.3 & 15.4 & & 1.7 \\
\hline \multirow[t]{2}{*}{ RCA } & $M$ & 43.7 & \pm & 4.7 & 2.96 & \pm & 0.4 & 15.7 & \pm & 1.6 \\
\hline & $\mathrm{F}$ & 43.7 & & 4.4 & 2.85 & & 0.3 & 15.4 & & 1.7 \\
\hline \multirow[t]{2}{*}{ LCX } & $M$ & 43.4 & \pm & 4.5 & 2.64 & \pm & 0.2 & 15.2 & \pm & 1.7 \\
\hline & $\mathrm{F}$ & 42.0 & & 5.3 & 2.67 & & 0.1 & 16.0 & & 1.0 \\
\hline
\end{tabular}

Data were presented as Mean \pm SD

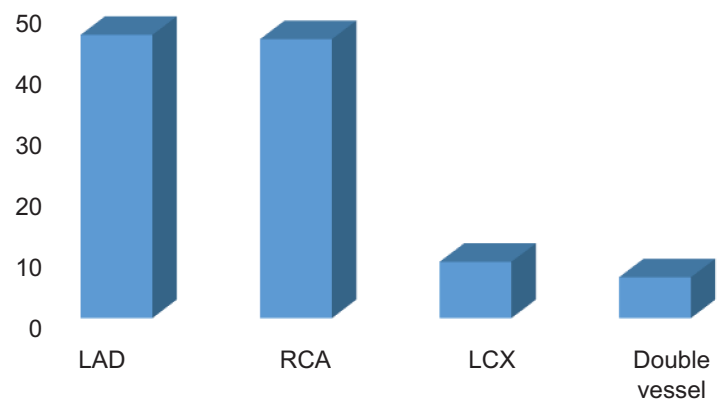

Fig.-1. Percentage of distribution of Coronary Stent

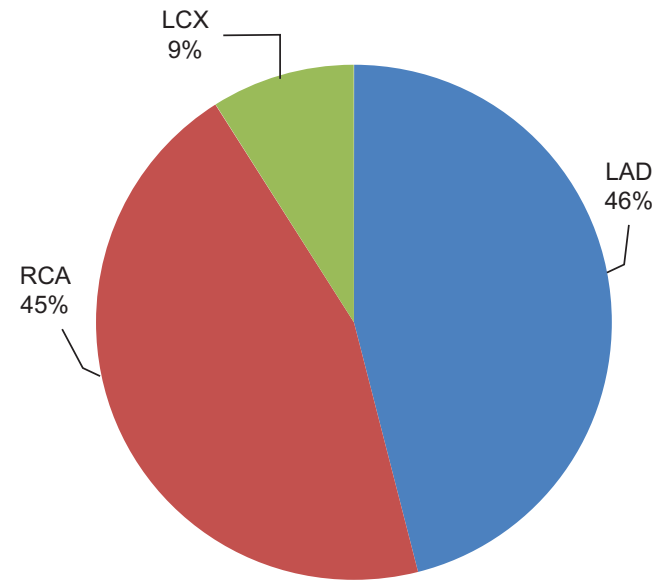

Fig.-2: Percentage of distribution of Stented territory

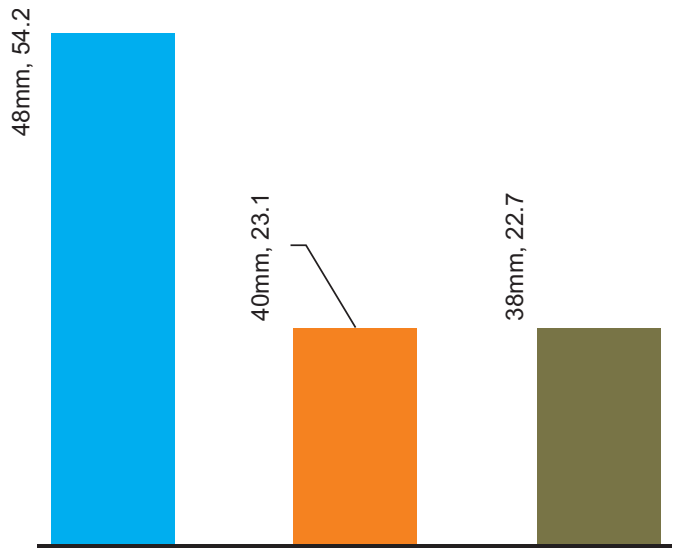

Fig.-3: Percentage distribution of Stent according to size

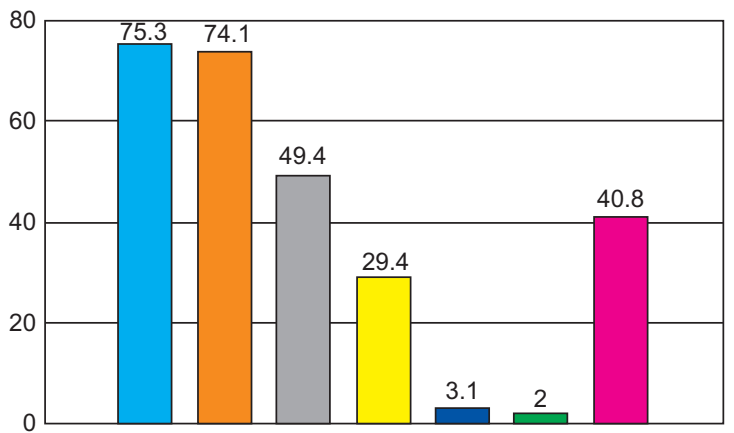

Fig.-4: Percentage of Distribution of CAD Risk Factors 
Stent positioning

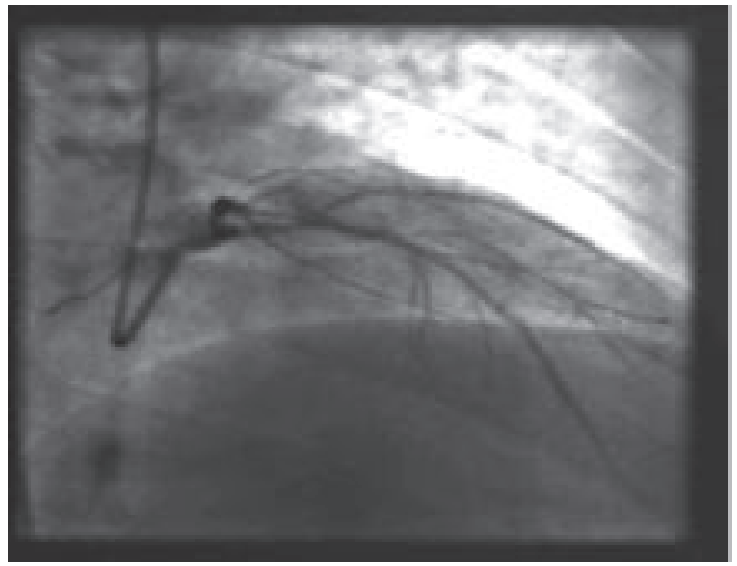

Post PCl

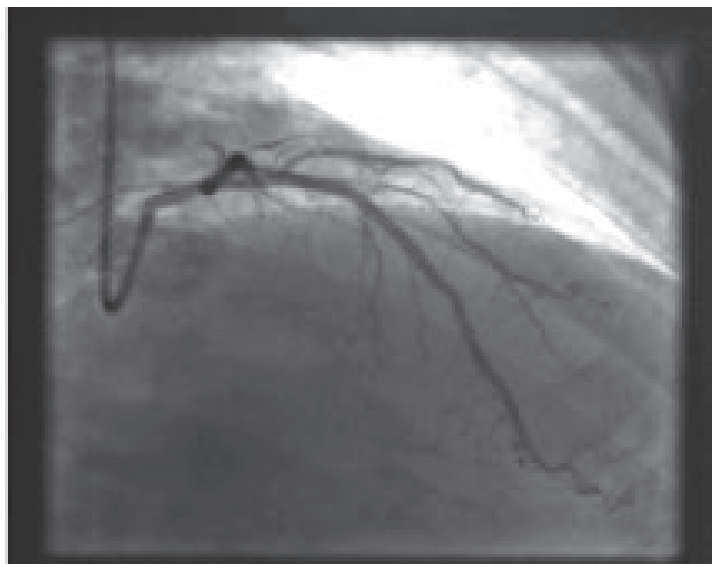

Fig.-5: Shows PCl of LAD lesion with $2.75 \times 48 \mathrm{~mm}$ Stent
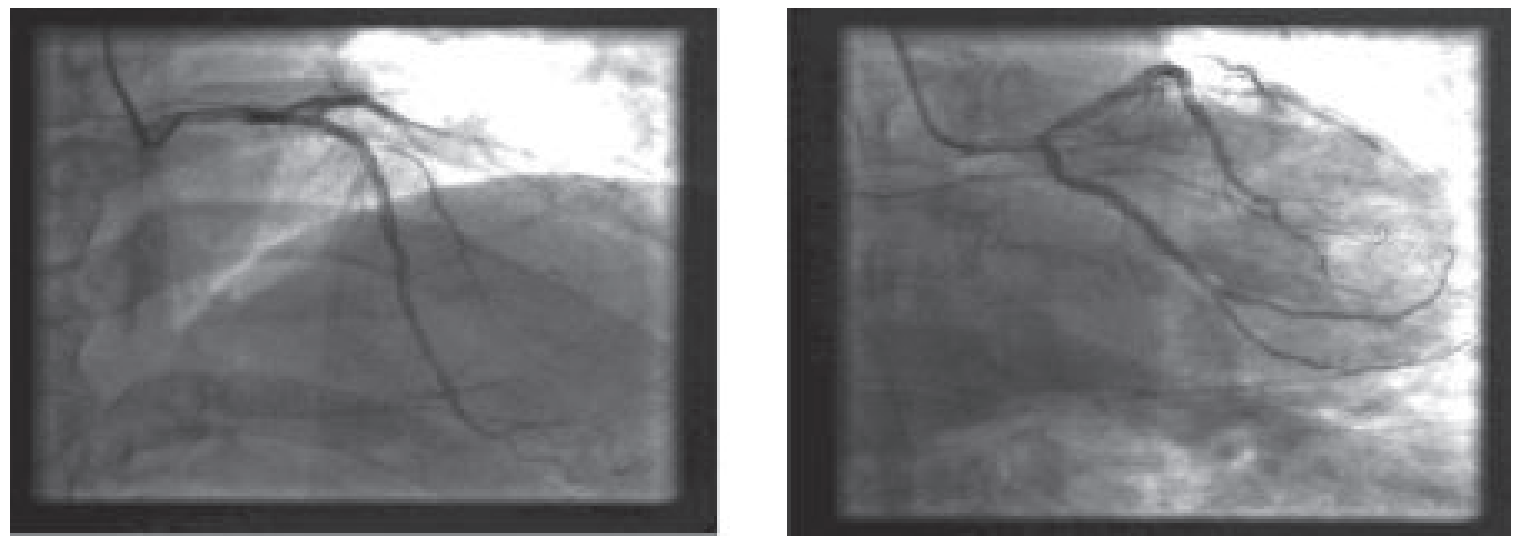

Fig.-6: Shows Patent $L A D$ and $L C X$ stent after 16 month

\section{Discussion:}

In the era of Percutaneous coronary intervention( $\mathrm{PCl})$ in treating long segment lesion, itself is an important predictor determinant of restenosis. Nonrandomized studies have indicated an increased risk of restenosis after conventional $\mathrm{PCl} .{ }^{13}$ Multiple or long coronary stents are now being used to treat long lesion or in tandem lesions and shown to have higher restenosis. ${ }^{6-7}$

In this current prospective cohort study, we try to find the stent patency and major adverse cardiac events (MACES) that is stent thrombosis, $\mathrm{Ml}$ or death after treating longsegment lesion by putting a long stent. In our study, females are more obese than male with poorly controlled diabetes possibly due to lack of exercise or non-compliance to medicine or ignorance. The number of CAD risk factors were more in male than female, possible due to smoking as additive factor in male. This is in favor that suggested, both male and female patients might have different CAD risk factors that trigger the development of coronary artery disease. Interestingly, the average vessel size in all three territories in both male and female were less than $3 \mathrm{~mm}$ in diameter. In general, we are treating small size vessel in our population where the chances of development of in-stent restenosis is high. ${ }^{14} \mathrm{Also}$, the post $\mathrm{PCl}$, Serum Creatinine level didn't change much than the pre PCI Serum Creatinine level, possibly due to controlled uses of ionic contrast uses amount during the entire procedure to keep as much low as possible. ${ }^{15}$

This is the first time; we have carried out this non randomized single center prospective cohort of patients underwent $\mathrm{PCl}$ for their occluded coronaries by a long single stent to treat the de novo long lesion. Previously, Islam et al, ${ }^{16}$ demonstrated treating a long segment lesion by multiple overlapping stents; where Sirolimus Eluting Stents (Cypher) 
showed reduce ISR than other DES. Since, ISR is one of the important drawback in maintaining the integrity of stent patency and thus patient's clinical improvement. So, we designed to treat long de novo lesion at our center by putting a single stents $>38 \mathrm{~mm}$ in length. We used three different stent size of $38 \mathrm{~mm}, 40 \mathrm{~mm}$ and $48 \mathrm{~mm}$. We did not find ISR at 1.5 years after $\mathrm{PCl}$ in this patient subset. Even though the average vessel diameter is less than $3 \mathrm{~mm}$, which is very common in this Asian population.

It is well known that dramatic advances in treating clogged coronary artery to open and keep its patency, thus to reduce myocardial damage either by $\mathrm{PCl}$,using bare metal stents or different drug eluting stents, leads to reduction CABG. ${ }^{13}$ It has been shown thatpercutaneous coronary intervention by stenting over plain PTCA has clear advantages in terms of restenosis, and restenosis driven events for an increasing number of indications. ${ }^{2-3}$ In addition, the administration of DAPT for given a given times, has dramatically reduces the development of stent thrombosis or subsequent ISR. ${ }^{16-18}$

Long lesion and long stent are considered as important predictors of restenosis after $\mathrm{PCl}$ with Bare metal stent (BMS) or Drug eluting stent (DES).DES have consistently shown to reduce restenosis, need for target lesion revascularization or MACE over the Bare metal stent (BMS). A number of nonrandomized studies have indicated an increased likelihood of restenosis after coronary stent implantation in treating long lesion. ${ }^{19-20}$ Longer lesion needs a longer stent to cover the lesion. This increase length may require the placement of $>1$ stent and may exacerbate the risk of restenosis, mask the direct relationbetween lesion length and lumen narrowing after coronary stenting.

The reason why the implantation of more stents causing more restenosis irrespective of lesion length and stented segment is not known. One possible explanation, is that are difficult to avoid unless intentionally overlapping the stents. Tissue prolapse may occur between stents in same as described for the articulation site of Palamz-schatz stents, ${ }^{21}$ has suggested spot stenting seems to be preferable over full jacket for $\mathrm{PCl}$ in long lesion. As stented length increases the chances of restenosis and stent thrombosis, since metal, polymer and drug disrupt the intimate morphology and physiology.Adnan kastrati et al has suggested in treating long lesion by a single long stent is favorable over multiple shorts stent. ${ }^{22}$

In our study, female patients are more obese, poorly controlled diabetes, developed CAD in advance age than male patients. Although, in our present study, average stent diameter is less than $3 \mathrm{~mm}$ in both male and female patients. Therefore, long lesion and small vessel diameter in addition to poorly controlled diabetes, specially in female and smoking in male (as all smoker) might be one of the important determinant in stent patency specially in long lesion.

In this study, we put all drug eluting stent in treating long lesion. Follow up CAG has shown no ISR at 1.5 years after $\mathrm{PCl}$ which is very much consistent with described else. ${ }^{23}$ Kereiakes et al ${ }^{24}$ showed that in the BMS group long lesion has the higher rate of ISR, similarly stent length and lesion length is an independent predictor of ISR in various DES. ${ }^{19,25}$

\section{Conclusion:}

Treating long segment coronary lesion, has some drawbacks due to the possibility of development of ISR. Previously, $\mathrm{PCl}$ by putting multiple overlapping stent was one of the important modality in treating long coronary lesion. But, the development or risk of possible in-stent restenosis, many has changes to one stent strategy to treat long lesion. With the advent of different DES in different length size and availability of IVUS, the ISR rate has come down. In this perspective non randomized single center cohort, we found treating long de novo coronary lesion by a single long drug eluting stent is safe, without any ISR at 1.5 year follow up in ourpatient population. Thus, to reduce hospital re-admission and reduce hospital cost as well.

\section{Future perspective:}

Our future plan is to enroll more patient to do long-term follow-up, to see stent patency and MACE in terms of ISR, $\mathrm{Ml}$ and death, and hence, if possible to enroll and compare multicenter involvement.

\section{References}

1. Roubin GS, Cannon AD, Agrawal SK et al. Intracoronary stenting for acute or threatened closure complicating percutaneous transluminal coronary angioplasty. Circulation 1992:85:916-27.

2. Fischman D, Leon MB, Baim DS et al. A randomized comparison of coronary stent placement and balloon asngioplasty in the treatment of coronary artery disease, N Engl J Med 1994:331:496-501.

3. Serruys $P$, Jaegree $P$, Kiemeneij $F$ et al. A comparison of balloon expandable stent implantation with balloon angioplasty in patients with coronary artery disease. N Engl J Med 1994; 331:496-501.

4. Colombo A, Goldberg SL, Almagor Y et al. A novel strategy for stent deployment in treatment of acute or threatened closure complicating balloon coronary angioplasty. Use of short standard or both single or multiple Palmaz-Schatz stents. J Am Coll Cardiol 1993; 22:1887-91. 
5. Kobayashi Y, De Gregorio J, et al. stented segment length as an independent predictor of restenosis. JACC 1999; 34:651-9.

6. Ellis SG, Savage M, Fischman D et al. Restenosis after placement of palmaz-Schatz stents in native coronary arteries. Initial results of a multicenter experience. Circulation 1992. 86:1836-44.

7. Strauss BH, Serryus PW, de Scheerder IK et al. Relative risk analysis of angiographic predictors of restenosis within the coronary wall stent Circulation 1991: 84:1636-43.

8. Nakamura S, Colombo A, Gaglione S et al. Intracoronary Ultrasound observations during implantation. Ciorculation. 1994; 89:2026-34.

9. Serryus PW, Foley DP and Materne $P$ et al: A randomized Comparison of the value of additional stenting after optional balloon angioplasdty for long coronary lesion: Final results of additional value of NIR stents for treatment of long coronary lesion. JACC 39:393-9.

10. Triantafullou, Ket al. Spot stenting is preferable in long diffuse coronary lesion: possible incremental value of physiologic and intracoronary imaging modalities. Hospital Chronicles 8:71-7.

11. Aoki J, Ong AT, Granili GR et al. Full metal jacket using drug eluting stents for de novo coronary lesion. Am Heart J 2005; 150:994-9.

12. Kim YH, Park SJ, Lee CW et al. Comparison of Sirolimus eluting stents, paclitaxel stents and bare metal stents in treating long coronary lesion. Cath card Interv 2006;67;181-7.

13. Schomig A, Kastrati A, Mudra $\mathrm{H}$ et al. Four year experiences with palmaz-Schatz stenting in coronary angioplasty complicated by dissection with threatened or present vessel closure. Circulation 1994; 90: 2716-24.

14. AHM Waliul Islam, Shams Munwar et al. Percutaneous coronary intervention in small vessel CAD in patients with Diabetes. Bangladesh Heart Journal. 2007;22(2):70-75.

15. AHM Waliul Islam, shams Munwar et al. Multiple or overlapping stent in single artery territory in
Bangladeshi patient population with patency and reduced ISR- a single center experiences. Cardiovasc. J $2012 ; 5(1): 18-22$.

16. AHM Waliul Islam, Shams Munwar, Azfar H Bhuiyan et al. Serum creatinine does not change much at $2^{\text {nd }}$ post PCI Intervention: amount of contrast injected may be the key factor. Cardiovasc J. 2017;9(2):155-158.

17. Schomig A, Neuman FJ, Kastrati Aet al. A randomized comparison of antiplatelet and anticoagulant therapy after the placement of coronary artery stents. $\mathrm{N}$ engl J Med 1996; 334:1084-9.

18. Leon MB, Baim DS, Pompa JJ et al. A climnical trial comparing three antithrombotic drug regimens after coronary artery stenting. N engl J Med. 1998; 339:1665-71.

19. Moussa I, Reimers B, Moses J et al. Long term clinical and angiographic outcome of patient undergoing Multivessel coronary stenting. Circulation 1997; 96:3873-79.

20. Hoffmann R, Mintz GS, Mehran R et al. Intravascular ultrasound predictors of angiographic restenosis in lesions treated with Palmaz-Schatz stents. J Am Coll Cardiol 1998;31: 43-49.

21. Hoffman R, Mintz GS, Dussailant GR et al. Patterns and mechanism of ISR. A serial intravascular ultrasound study. Circulation 1996:94:1247-54.

22. Adnan Kastrati, ShpendElezi and Dirschinger $\mathrm{J}$ et al. Influence of Lesion length on restenosis after coronary stent placement. Am J Cardiol 1999; 83:1617-22.

23. Chang $\mathrm{SH}$, Chen $\mathrm{CC}, \mathrm{Hsieh} \mathrm{Mj}$, et al. Lesion length impacts long term outcomes of drug eluting stents and bare metal stents differently.PLOS ONE;2013: 8(1) E53207.

24. Kereiakes D, Linnemeier TJ, Baim DS et al. Usefulness of stent length in predicting in stent restenosis (the MULTILINK stent trials). Am J Cardiol 2000. 86:336-41.

25. Marui L, O'alley AJ, Pompa JJ etr al. Comparison of thrombosis and restenosis risk from stent length of Sirolimus eluting stents vs bare metal stents. Am J Cardiol 2005. 95:1140-45. 